\title{
45. DATA REPORT: PHYSICAL PROPERTIES OF MASSIVE SULFIDE FROM SITE 856, MIDDLE VALLEY, NORTHERN JUAN DE FUCA RIDGE ${ }^{1}$
}

\author{
Henrike M. Gröschel-Becker, ${ }^{2}$ Earl E. Davis, ${ }^{3}$ and James M. Franklin ${ }^{4}$
}

\begin{abstract}
The results of eight high-pressure velocity experiments and eight divided-bar thermal-conductivity measurements on massive sulfide samples recovered from Ocean Drilling Program Holes $856 \mathrm{G}$ and $856 \mathrm{H}$ are presented. Densities, porosities, velocities, and thermal conductivities are highly variable owing to textural and mineralogical variations and the highly porous nature of most of the five types of sulfide reported on here. Porosity occurs as open to partially filled intergranular spaces, vugs, veins, cracks, and fractures. Sulfide samples are not ideal for either high-pressure velocity experiments or divided-bar thermal-conductivity measurements; limitations and sources of potential error are discussed in the text. Sample geometry and textural makeup particularly caused problems in the velocity experiments. The lack of a suitable shipboard high-conductivity standard also contributed to errors, as is apparent from a comparison of the shore-based divided-bar data with shipboard half-space measurements conducted on the same samples. These velocity and thermal-conductivity data, are, to the best of our knowledge, the first to be reported for massive sulfides in the open literature.
\end{abstract}

\section{INTRODUCTION}

The penetration of more than $159 \mathrm{~m}$ of massive sulfide at Bent Hill, Middle Valley, at Ocean Drilling Program (ODP) Holes 856G and $856 \mathrm{H}$ provided an unusual opportunity for the study of the physical properties of a deposit that probably precipitated at and above the seafloor. Compressional $\left(V_{p}\right)$ - and shear $\left(V_{s}\right)$-wave velocities of eight oriented massive sulfide minicore cylinders were measured at varying confining pressures using a pulse-transmission technique similar to that of Birch $(1960,1961)$. Two samples were from Hole $856 \mathrm{G}$ and six were from Hole $856 \mathrm{H}$ (Table 1). Bulk densities $\left(\rho_{b}\right)$ and porosities were also determined. Results are presented for a Hole $856 \mathrm{G} / \mathrm{Hole}$ $856 \mathrm{H}$ composite section since the two boreholes were drilled no more than $20 \mathrm{~m}$ apart (Shipboard Scientific Party, 1992b). A shore-based divided-bar apparatus was used to obtain thermal conductivities of eight $2-\mathrm{cm}^{3}$ cubes of massive sulfide cut for shipboard physical properties measurements (Table 2).

\section{SAMPLE DESCRIPTION}

Samples are described according to the sulfide classification scheme developed aboard the ship (Figs. 87 and 88, Shipboard Scientific Party, 1992b). Velocity measurements were conducted on two type 1 samples (homogenous, massive, fine-grained pyrrhotite), two type 4 samples (heterogenous and veined, coarse-grained pyrite-pyrrhotite), and four type 5 samples (massive colloform and vuggy pyrite). Thermal conductivities were determined for two cubes of type 4, two of type 5, two of type 2 (homogeneous, massive, fine-grained pyrite-pyrrhotite), and two of type 3 (homogeneous, medium- to coarse-grained pyrite-pyrrhotite).

The average grain density $\left(\rho_{g}\right)$ of our samples is high $\left(4.52 \mathrm{~g} / \mathrm{cm}^{3}\right)$. Variable proportions of pyrite $\left(\rho_{g=}=4.92 \mathrm{~g} / \mathrm{cm}^{3}\right)$, pyrrhotite $\left(\rho_{g}=4.55\right.$ $\left.\mathrm{g} / \mathrm{cm}^{3}\right)$, and magnetite $\left(\rho_{g}=5.15 \mathrm{~g} / \mathrm{cm}^{3}\right)$ (Horai, 1971), $10 \%-25 \%$ of which is present in type 4 and 5 rocks, result in high $\rho_{g}$ and $\rho_{b}$ values. Successive replacement of "primitive" type 1 sulfide to "mature" type

\footnotetext{
${ }^{1}$ Mottl, M.J., Davis, E.E., Fisher, A.T., and Slack, J.F. (Eds.), 1994. Proc. ODP. Sci. Results, 139: College Station, TX (Ocean Drilling Program).

${ }^{2}$ Division of Marine Geology and Geophysics, Rosenstiel School of Marine and Atmospheric Science, University of Miami, 4600 Rickenbacker Causeway, Miami, FL 33149-1098, U.S.A.

${ }^{3}$ Geological Survey of Canada, Pacific Geoscience Centre, P.O. Box 6000, Sidney, British Columbia V8L 4B2, Canada.

${ }^{4}$ Geological Survey of Canada, 601 Booth Street, Ottawa, Ontario K1A 0E8, Canada.
}

4 and type 5 sulfide occurs through progressive dissolution, replacement, and reprecipitation of primary pyrrhotite with pyrite, chalcopyrite, sphalerite, and magnetite (Shipboard Scientific Party, 1992b). Chalcopyrite and sphalerite have considerably lower grain densities ( 4.09 and $4.10 \mathrm{~g} / \mathrm{cm}^{3}$, respectively), than the other sulfide minerals (Horai, 1971), are common as late-stage, coarse-grained crystals in type 4 sulfide and, with abundant veining, cause its heterogenous, commonly porous, texture. In contrast, the typical reticulate boxwork texture of type 5 sulfide, with prismatic pores of 0.1-2.0 mm diameter, results from pyrite precipitated after dissolution of precursor sulfide. Open vugs $2-4 \mathrm{~mm}$ in diameter commonly comprise up to $10 \%$ of this sulfide type. Pyrite dominates, and other sulfiđes are minor. Open porosity of up to $50 \%$ by volume occurs in type 1 sulfide as a consequence of interpenetrating fine-grained blades of dominant pyrrhotite. Chalcopyrite and sphalerite are ubiquitous and occur interstitially to the pyrrhotite and minor (usually less than $10 \%$ ) pyrite. Percentages of nonopaque minerals, including green smectite, chlorite, amorphous silica, and carbonate, occur interstitially most commonly in types 1-3 and also are present as vein and vug infill in types 4 and 5 , where white amorphous silica and chlorite typically form $15 \%$ of the rock.

\section{METHODS}

Velocity experiments were performed on oriented minicores in the Rosenstiel School of Marine and Atmospheric Science (RSMAS) Petrophysics Laboratory at hydrostatic pressures from 3 to $100 \mathrm{MPa}$. Wet-bulk densities and porosities were also obtained. Sample preparation and experimental methods were generally the same as those described in Gröschel-Becker et al. (this volume). Preparation of the samples was difficult owing to textural variations and surface irregularities, especially for type 5 (massive colloform and vuggy pyrite) sulfides. The polishing required before the samples were loaded into the velocimeter varied from minimal for relatively soft pyrrhotiterich samples to extensive for the hard, dense, massive pyrite.

Thermal conductivities of oriented cube samples were measured on a divided-bar apparatus at the Pacific Geoscience Centre (PGC) following the general procedures outlined in Davis and Seemann (this volume). Cross-sectional areas and thicknesses of all samples were derived from caliper measurements of the cubes. A minor amount of polishing was done on sample faces to ensure good thermal contact. Samples with broken edges or corners were not included in the study. 
Table 1. Variations in densities and compressional- and shear-wave velocities for massive sulfide minicore samples from Holes $856 \mathrm{G}$ and $856 \mathrm{H}$

\begin{tabular}{|c|c|c|c|c|c|c|c|c|c|c|c|c|c|c|}
\hline \multirow{2}{*}{$\begin{array}{l}\text { Core, section, } \\
\text { interval }(\mathrm{cm})\end{array}$} & \multirow[b]{2}{*}{ Direction } & \multirow{2}{*}{$\begin{array}{l}\text { Rock } \\
\text { type }\end{array}$} & \multirow{2}{*}{$\begin{array}{l}\text { Density } \\
\left(\mathrm{g} / \mathrm{cm}^{3}\right)\end{array}$} & \multirow[b]{2}{*}{ Mode } & \multicolumn{5}{|c|}{ Velocity $(\mathrm{m} / \mathrm{s})$} & \multicolumn{5}{|c|}{ Pressure (MPa) } \\
\hline & & & & & 10 & 20 & 30 & 40 & 50 & 60 & 70 & 80 & 90 & 100 \\
\hline \multirow{2}{*}{\multicolumn{15}{|c|}{$\begin{array}{l}139-856 \mathrm{G}- \\
\quad 7 \mathrm{R}-4,15-17\end{array}$}} \\
\hline & h & $5: \mathrm{Py}$ & 3.86 & $\mathrm{P}$ & 4990 & 5020 & 5050 & 5070 & 5080 & 5100 & 5150 & 5150 & 5130 & 5120 \\
\hline \multirow{4}{*}{$7 R-4,18-20$} & & & & S1 & 2710 & 2750 & 2790 & 2860 & 2960 & 3050 & 3120 & 3120 & 3120 & 3120 \\
\hline & $\mathrm{v}$ & 5:Py & 4.00 & $\mathrm{P}$ & 6950 & 7100 & 7150 & 7180 & 7200 & 7230 & 7250 & 7280 & 7300 & 7300 \\
\hline & & & & SI & 3510 & 3540 & 3610 & 3650 & 3710 & 3780 & 3830 & 3840 & 3800 & 3770 \\
\hline & & & & $\mathrm{S} 2$ & 3650 & 3670 & 3720 & 3750 & 3780 & 3820 & 3860 & 3870 & 3840 & 3830 \\
\hline \multicolumn{15}{|l|}{$139-856 \mathrm{H}-$} \\
\hline \multirow{3}{*}{$3 R-1,18-21$} & $\mathrm{v}$ & 4:Py/Po & 4.01 & $\mathrm{P}$ & 5860 & 5900 & 5940 & 5970 & 5990 & 6030 & 6060 & 6080 & 6090 & 6120 \\
\hline & & & & S1 & 3270 & 3310 & 3320 & 3340 & 3350 & 3360 & 3380 & 3390 & 3390 & 3390 \\
\hline & & & & S2 & 3180 & 3200 & 3240 & 3250 & 3260 & 3280 & 3300 & 3300 & 3310 & 3310 \\
\hline \multirow[t]{3}{*}{$3 \mathrm{R}-1,24-27$} & $\mathrm{~h}$ & 4:Py/Po & 3.90 & $\mathrm{P}$ & 5890 & 5970 & 6000 & 6030 & 6060 & 6090 & 6120 & 6140 & 6150 & 6150 \\
\hline & & & & S1 & 3280 & 3300 & 3320 & 3320 & 3330 & 3330 & 3360 & 3410 & 3350 & 3350 \\
\hline & & & & $\mathrm{S} 2$ & 3220 & 3230 & 3240 & 3420 & 3250 & 3260 & 3280 & 3280 & 3290 & 3290 \\
\hline \multirow[t]{3}{*}{$10 \mathrm{R}-1,52-55$} & $\mathrm{~h}$ & $5: \mathrm{Py}$ & 3.85 & $\mathrm{P}$ & 6190 & 6350 & 6480 & 6600 & 6670 & 6760 & 6890 & 6940 & 6960 & 6990 \\
\hline & & & & S1 & 3500 & 3530 & 3570 & 3680 & 3640 & - & - & - & 3660 & 3680 \\
\hline & & & & $\mathrm{S} 2$ & 3330 & 3510 & 3590 & 3650 & 3660 & 3690 & 3750 & 3790 & 3840 & 3870 \\
\hline \multirow[t]{3}{*}{$10 \mathrm{R}-1,56-58$} & $v$ & 5:Py & 3.49 & $\mathrm{P}$ & 6430 & 6530 & 6600 & 6660 & 6730 & 6840 & 6910 & 6950 & 6980 & 6990 \\
\hline & & & & S1 & 3220 & 3260 & 3310 & 3350 & 3370 & 3390 & 3430 & 3440 & 3450 & 3390 \\
\hline & & & & S2 & 3210 & 3230 & 3250 & 3260 & 3290 & 3300 & 3400 & 3460 & 3460 & 3370 \\
\hline \multirow{3}{*}{$15 \mathrm{R}-1,16-18$} & $\mathrm{~h}$ & 1:Po & 3.63 & $\mathrm{P}$ & 3170 & 3220 & 3310 & 3350 & 3420 & 3450 & 3450 & 3460 & 3490 & 3500 \\
\hline & & & & S1 & 1790 & 1840 & 1850 & - & 1880 & 1900 & 1920 & 1920 & 1930 & 1930 \\
\hline & & & & & 1580 & 1660 & 1740 & 1780 & 1860 & 1890 & 1890 & 1900 & 1910 & 1920 \\
\hline \multirow[t]{3}{*}{$15 \mathrm{R}-1,20-22$} & $v$ & 1:Po & 3.60 & $\mathrm{P}$ & 3350 & 3400 & 3460 & 3500 & 3540 & 3580 & 3600 & 3630 & 3650 & 3670 \\
\hline & & & & S1 & 1710 & 1770 & 1810 & 1840 & 1870 & 1900 & 1930 & 1940 & 1960 & 1970 \\
\hline & & & & S2 & 1780 & 1820 & 1850 & 1880 & 1900 & 1920 & 1950 & 1960 & 1980 & 1990 \\
\hline
\end{tabular}

Note: $\mathrm{h}=$ horizontal minicore oriented perpendicular to core axis; $\mathrm{v}=$ vertical minicore oriented parallel to core axis; $\mathrm{Py}=\mathrm{pyrite} ; \mathrm{Py} / \mathrm{Po}=\mathrm{pyrite} / \mathrm{pyrrhotite}$; $\mathrm{Po}=$ pyrrhotite $\mathrm{P}=$ compressional wave; $\mathrm{S} 1$ = shear wave propagating perpendicular to minicore alignment direction; $\mathrm{S} 2=$ shear wave propagating parallel to minicore alignment direction.

Table 2. Thermal conductivities, porosities, and major constituent minerals of sulfide cubes samples from Holes $856 \mathrm{G}$ and $856 \mathrm{H}$.

\begin{tabular}{|c|c|c|c|c|c|c|}
\hline $\begin{array}{l}\text { Core, section, } \\
\text { interval }(\mathrm{cm})\end{array}$ & $\begin{array}{l}\text { Piece } \\
\text { no. }\end{array}$ & $\begin{array}{l}\text { Depth } \\
\text { (mbsf) }\end{array}$ & Type/lithology & $\begin{array}{c}\text { Shipboard } \\
\text { porosity } \\
(\%)\end{array}$ & $\begin{array}{l}\text { Shipboard } \\
\text { thermal } \\
\text { conductivity } \\
(\mathrm{W} / \mathrm{m}-\mathrm{K})\end{array}$ & $\begin{array}{l}\text { PGC thermal } \\
\text { conductivity } \\
(\mathrm{a}+\mathrm{b}+\mathrm{c}) \\
(\mathrm{W} / \mathrm{m}-\mathrm{K})\end{array}$ \\
\hline \multicolumn{7}{|l|}{$139.856 \mathrm{G}-$} \\
\hline $3 R-1,39$ & 6 & 17.9 & Type 2: homogeneous massive fine-gr. pyrite-pyrrhotite & 11.9 & 6.2 & 6.8 \\
\hline $4 \mathrm{R}-1,34$ & 5 & 27.2 & Type 3: homogeneous medium- to coarse-gr. pyrite-pyrrhotite & 17.8 & 3.6 & 5.9 \\
\hline $6 \mathrm{R}-1,140$ & 23 & 47.7 & Type 3 : homogeneous medium- to coarse-gr. pyrite-pyrrhotite & 17.6 & & 7.8 \\
\hline $7 \mathrm{R}-4,49$ & 5 & 60.6 & Type 5: massive colloform and vuggy pyrite & 14.0 & 7.2 & 13.4 \\
\hline \multicolumn{7}{|l|}{$139.856 \mathrm{H}-$} \\
\hline $3 \mathrm{R}-1,16$ & 2 & 22.3 & Type 4 : heterogenous and veined coarse-gr. pyrite-pyrrhotite & 6.9 & 3.8 & 7.3 \\
\hline $3 R-3,107$ & 9 & 25,8 & Type 4 : heterogenous and veined coarse-gr. pyrite-pyrrhotite & 16.8 & 4.1 & 5.1 \\
\hline $9 \mathrm{R}-1,59$ & 8 & 53.1 & Type 5: massive colloform and vuggy pyrite & 22.2 & 6.3 & 12.1 \\
\hline $13 \mathrm{R}-1,40$ & 5 & 71.3 & Type 2: homogenous massive fine-gr. pyrite-pyrrhotite & 16.8 & 4.6 & 6.5 \\
\hline
\end{tabular}

\section{EXPERIMENTAL LIMITATIONS}

Massive sulfides are, in general, not ideal samples for high-pressure velocity experiments. Surface irregularities owing to vugs, microcracks, and partially to fully filled veins, prevented optimum contact of the transducers with the cylinder faces and reduced the accuracy of the measurements, especially $V_{s}$. The saturating fluid may have partially drained from these porous samples prior to measurement, resulting in lower $V_{p}$ than expected at saturated conditions for the relatively low pressures used in this study; the effect of saturation on $V_{s}$ is negligible (Christensen and Salisbury, 1975, and references therein; Bonner and Schock, 1981). These two problems were most apparent in type 5 sulfides. Repeat measurements were not possible because four of eight samples failed at pressures between 70 and $90 \mathrm{MPa}$. In general, sulfide $V_{p}$ and $V_{s}$ results are good to $1 \%$ to $2 \%$ up to $80 \mathrm{MPa}$; velocities of intact igneous rocks are good to $1 \%$.

The greatest source of error in the measurement of conductivity of these samples probably arises from thermal contact resistances. A viscous wetting agent was used on the cube faces to reduce this error because the small temperature difference across the highly conductive massive sulfide cubes (on the order of $0.5 \mathrm{~K}$ ) relative to that across the standard samples of the bar (typically 3-4 K), makes any temperature drop across the imperfect contacts significant. Oriented cubes were cut from split core sections with a twin-blade cut-off saw (Shipboard Scientific Party, 1992a); hence, the two pairs of opposing faces normal to the long core (a) axis and normal to the split core face (b axis) were generally quite parallel (Fig. 1). The greatest nonparallelism occurred between the split face and its opposite side (normal to the $\mathrm{c}$ axis); imperfections of most samples could be accommodated by the gimbaled mount of the upper part of the divided-bar apparatus. Repeat measurements were made in several cases where the a-, b-, and c-axis values differed by more than $10 \%$ to $20 \%$. No large or systematic differences were observed in the measurements along any of the three axes, and the values given in Table 2 are average values.

\section{RESULTS}

\section{Density, Porosity, and Velocity}

Wet-bulk densities of the eight velocity samples range from 3.49 $\mathrm{g} / \mathrm{cm}^{3}$ to $4.01 \mathrm{~g} / \mathrm{cm}^{3}$; the greatest variations occur in type 5 sulfides (Table 1). Porosities are high, from $10.6 \%$ in type 4 Sample 139 $856 \mathrm{H}-3 \mathrm{R}-1,18-21 \mathrm{~cm}$, to $28.3 \%$ in type 5 Sample $139-856 \mathrm{H}-10 \mathrm{R}-1$, 


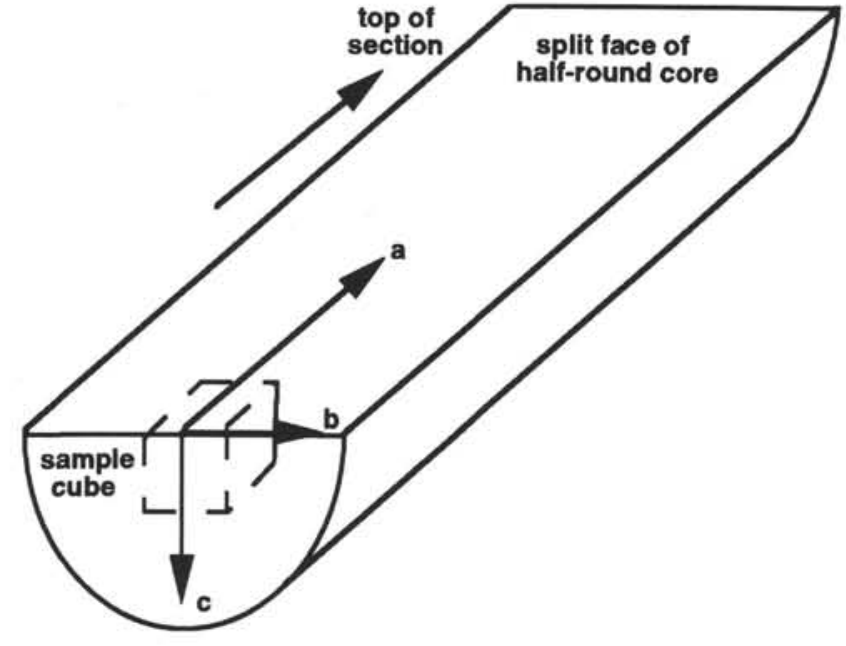

Figure 1. Shipboard convention for orientation of cube samples taken from the working halves of consolidated sediment or hard-rock cores. The a axis is parallel to the vertical axis of the core section, the $b$ axis is across the core parallel to the split core face, and the $\mathrm{c}$ axis is through the core perpendicular to the split core face.

$56-58 \mathrm{~cm}$ (Table 2). The average porosity of type 5 pyrite rocks is $24.7 \%$. Differences in these two properties between adjacent horizontally and vertically oriented sulfide minicores are apparent in Figure 2 , which plots wet-bulk density and porosity vs. depth in a Site 856 composite section. Shipboard cube values are plotted for comparison; these and porosity data were recalculated using dry volumes only to be consistent with shore-based values. Density variations of up to $9.9 \%$ between nearby samples and observed velocity variations reflect differences in textures, porosity resulting from the prevalence of open and partially filled intergranular pore spaces, vugs, veins, cracks, and fractures, and infilling by nonopaque minerals, as well as variable percentages of sulfide minerals.

\section{Thermal Conductivity}

The sulfide conductivities span a large range, from 5.9 to 13.4 $\mathrm{W} / \mathrm{m}-\mathrm{K}$. The two highest values were measured on samples consisting primarily of pyrite, a mineral that has a particularly high thermal conductivity of $19.2 \mathrm{~W} / \mathrm{m}-\mathrm{K}$ (Horai, 1971). Others contain significant amounts of pyrrhotite, carbonate, silica, and other thermally less conductive minerals, which appears to be the primary reason for their relatively lower conductivities. Detailed petrographic analyses of our samples are needed to analyze the effects of intergranular structure in terms of grain contacts and its relation to conductivity and the systematics of pyrite and other constituent minerals.

Porosities range from $7 \%$ to $22 \%$, and although the contrast in thermal conductivity between any of the constituent minerals and water is large, variations in porosity alone cannot account for the variation in conductivity. This is seen clearly in Figure 3, in which the measured thermal conductivities of the samples are plotted against their porosities, as are the relationships predicted by a simple geometric mean mixing law (e.g., Brigaud and Vasseur, 1989) with various constituent mineral conductivities and the conductivity of water of 0.6 $\mathrm{W} / \mathrm{m}-\mathrm{K}$. The conductivity of $19.2 \mathrm{~W} / \mathrm{m}-\mathrm{K}$ for pure pyrite produces the upper curve; use of a value of $9.0 \mathrm{~W} / \mathrm{m}-\mathrm{K}$ results in a reference curve that provides a crude lower bound for the sulfide data, assuming that the mean harmonic model can be applied. A value of $2.6 \mathrm{~W} / \mathrm{m}-\mathrm{K}$ provides the best fit for the sediment and igneous data. Despite the wide range of implied constituent conductivity values, the minimum value is still high, three times the value inferred from the conductivities and porosities measured on sediment and basalt samples (Davis and Seemann, this volume; shown also in Fig. 3 for comparison).

As is discussed previously, the set-up of the divided-bar apparatus used in this study was not ideal for the measurement of metallic sulfide rocks having high thermal conductivity. The largest source of systematic error is expected to be associated with thermal contact resistance, which would cause values to be erroneously low. An upper limit for the magnitude of such an error can be estimated by calculating the effect of a $0.1-\mathrm{mm}$ gap between the sample and the brass contact plate filled with contact gel having a thermal conductivity of $1 \mathrm{~W} / \mathrm{m}-\mathrm{K}$. This would introduce an error of $5 \%$ into the determination
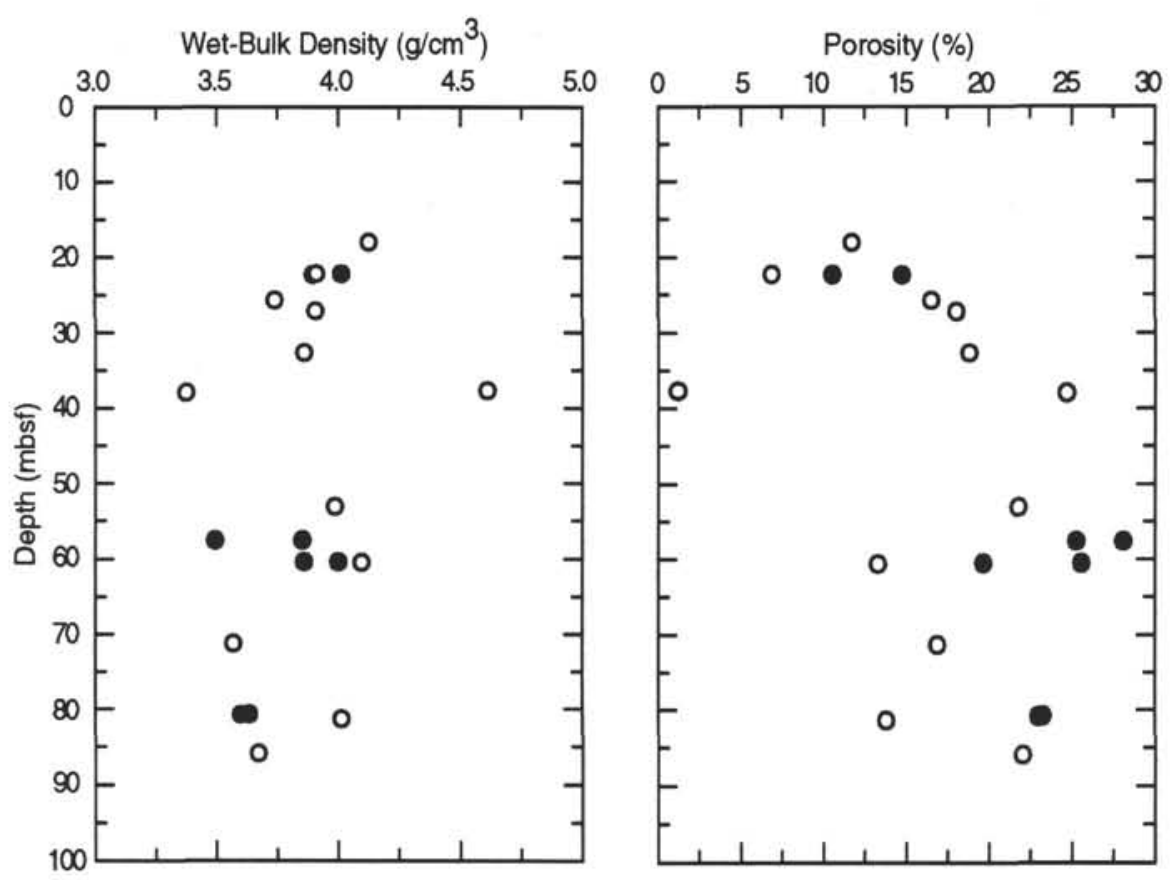

Figure 2. Wet-bulk density vs. depth and porosity vs. depth for a Site 856 composite sulfide section. Filled circles represent data from this study; open circles represent shipboard data. 


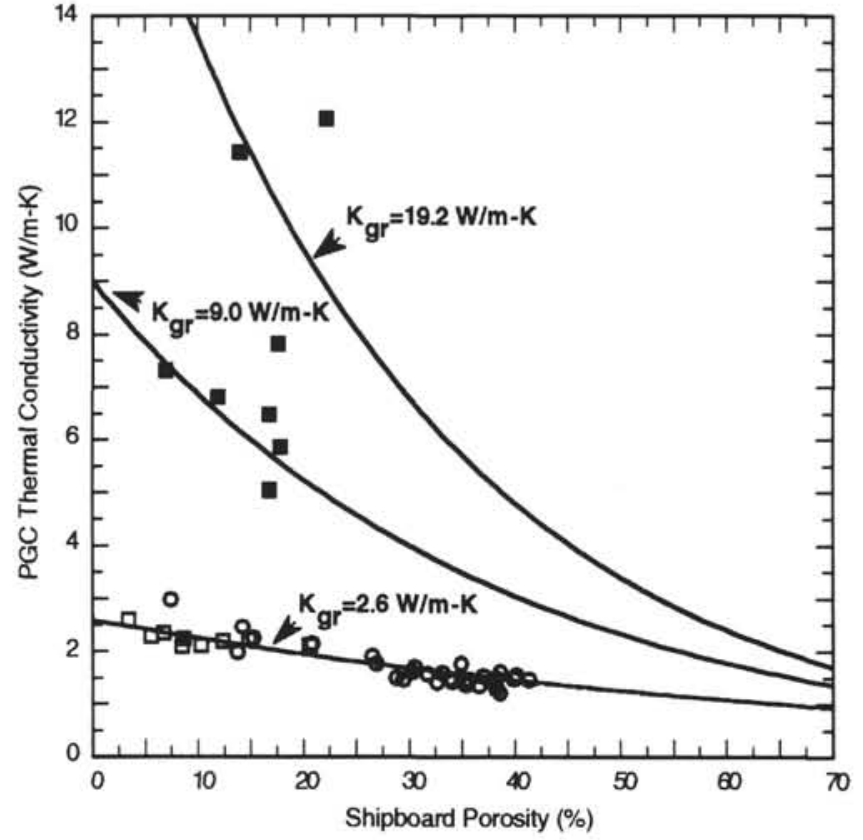

Figure 3. Divided-bar thermal conductivity vs. shipboard porosity for sulfide (filled squares), igneous (open squares), and sedimentary (circles) rocks from Middle Valley. Geometric mean mixing relationships, using three different constituent mineral conductivities $(19.2,9.0$, and $2.6 \mathrm{~W} / \mathrm{m}-\mathrm{K})$ plus water $(0.6$ $\mathrm{W} / \mathrm{m}-\mathrm{K})$, are shown as solid lines and are explained in detail in the text. Data for igneous and sedimentary rocks are taken from Davis and Seemann (this volume). Data for sulfide rocks are given in Table 2.

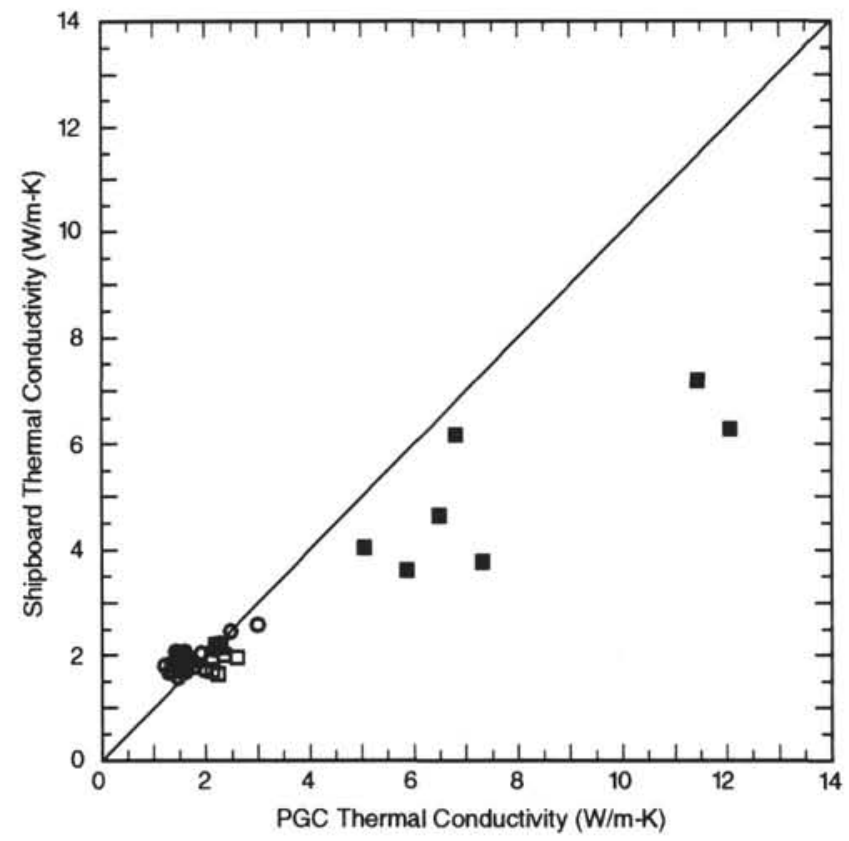

Figure 4. Shipboard thermal conductivity determined with a line source imbedded in a half-space vs. shore-based conductivity determined with a divided bar. Data sources and symbol conventions are the same as in Figure 3. of the conductivity of a $2-\mathrm{cm}^{3}$ rock sample with a conductivity of 10 $\mathrm{W} / \mathrm{m}-\mathrm{K}$. A comparison of the divided-bar measurements reported here with the line-source shipboard measurements reveals a discrepancy of the opposite sense and of a much larger magnitude (Fig. 4). This result is not surprising, as the method of measuring conductivity with a line-source imbedded in a half-space involves an empirically determined calibration factor determined over a range of conductivities that was limited relative to the values for the sulfide rocks at Site 856 (0.96 to 2.05 W/m-K; Shipboard Scientific Party, 1992a). Concern about this potential source of error was also expressed at the time the shipboard measurements were made (see Shipboard Scientific Party, 1992b). The error associated with this approximation increases with increasing conductivity; shipboard estimates (table 37, Shipboard Scientific Party, 1992b) are roughly half those determined with the divided bar at the highest conductivities. A significant systematic error appears to persist down to values in the region of $3 \mathrm{~W} / \mathrm{m}-\mathrm{K}$; shipboard values are about $10 \%$ lower. No systematic difference exists between measured values below $2 \mathrm{~W} / \mathrm{m}-\mathrm{K}$, the range over which calibration standards are available.

The velocity and thermal conductivity data, are, to the best of our knowledge, the first to be reported for massive sulfides in the open literature. Electrical resistivity measurements on cube samples are planned.

\section{ACKNOWLEDGMENTS}

HGB thanks R. Zierenberg for his tireless assistance in sample selection and enthusiasm for sulfide physical properties, and JOI/ USSAC for providing post-cruise funding; Gregor Eberli and Jim Natland graciously made their labs available. T. Lewis kindly provided EED with the divided bar apparatus.

\section{REFERENCES $*$}

Birch, F., 1960. The velocity of compressional waves in rocks to 10 kilobars, 1. J. Geophys. Res., 65:1083-1102.

, 1961 . The velocity of compressional waves in rocks to 10 kilobars, 2. J. Geophys. Res., 66:2199-2224.

Bonner, B.P., and Schock, R.N., 1981. Seismic wave velocity. In Touloukian, Y.S., and Ho, C.Y. (Eds.), Physical Properties of Rocks and Minerals: McGraw-Hill/CINDAS Data Series on Material Properties, II-2:221-256.

Brigaud, F., and Vasseur, G., 1989. Mineralogy, porosity and fluid control on thermal conductivity of sedimentary rocks. Geophys. J., 98:525-542.

Christensen, N.I., and Salisbury, M.H., 1975. Structure and constitution of the lower oceanic crust. Rev. Geophys. Space Phys., 13:57-86.

Horai, K., 1971. Thermal conductivity of rock-forming minerals. J. Geophys. Res., 76:1278-1308.

Shipboard Scientific Party, 1992a. Explanatory notes. In Davis, E.E., Mottl, M.J., Fisher, A.T., et al., Proc. ODP, Init. Repts., 139: College Station, TX (Ocean Drilling Program), 55-97.

, 1992b. Site 856. In Davis, E.E., Mottl, M.J., Fisher, A.T., et al., Proc. ODP, Init. Repts., 139: College Station, TX (Ocean Drilling Program), 161-281.

\footnotetext{
- Abbreviations for names of organizations and publications in ODP reference lists follow the style given in Chemical Abstracts Service Source Index (published by American Chemical Society).
}

Date of initial receipt: 13 January 1993

Date of acceptance: 28 April 1993

Ms 139SR-249 